Ann. Biol. anim., Bioch. Biophy's., I965, 5 (I), 79-100.

\title{
INFLUENCE DE L'ÉLÉVATION DU TAUX DE MATIÈRE SĖCHE SUR L'ÉVOLUTION BIOCHIMIQUE ET BACTÉRIOLOGIQUE D'UNE LUZERNE CONSERVÉE PAR ENSILAGE
}

\author{
Ph. GOUET, Nathalie FATIANOFF, S. Z. ZELTER, \\ Michelle DURAND et R. CHEVALIER
}

avec la collaboration technique de Mites Christiane Dumay, Nadine Mounous et Françoise Janot

\begin{abstract}
Laboratoire de Recherches sur la Conservation et l'Efficacité des Aliments, Laboratoire de Recherches de la Chaire de Microbiologie, Institut national agronomique, 16 , rue Claude-Bernard, Paris $\left(V^{\mathrm{e}}\right)$,
\end{abstract}

\section{SOMMAIRE}

Une deuxième coupe de luzerne a été ensilée à différents taux de matière sèche (I9,9 témoin $25,2-3 \mathrm{I}, 7-35,8-39,2$ p. I00) obtenus en prolongeant la durée du préfanage.

Pour chaque traitement, est étudiée parallèlement l'évolution (durant 98 jours) des phénomènes biochimiques (glycolyse-protéolyse) et des phénomènes microbiologiques (microflore totale, Gram positive et anaérobie sporulée, et différentes souches de la microflore lactique).

Le préfanage entraîne un ralentissement du taux de croissance, de la microflore totale, une diminution de la croissance totale et une inhibition du développement des Clostridia. Des modifications qualitatives sont enregistrées : élévation de la proportion de " lactiques " dans la microflore totale, abaissement de celle de lactobacilles dans la microflore Gram positive au profit des streptocoques, et augmentation des proportions de L. plantarum et de Str. faecalis. La fermentation acétique des ensilages préfanés s'en trouve réduite, et la fermentatien butyrique est inexistante à partir d'un taux de matière sèche de 3 I p. roo. La production d'acide lactique est retardée, réduite, mais continue tout au long de la conservation contrairement au témoin.

Le catabolisme des acides aminés et l'ammoniogenèse sont nettement plus atténués que la dégradation des protéines.

Un taux de 35 p. roo de matière sèche semble être suffisant dans nos conditions expérimentales pour orienter favorablement la conservation.

\section{INTRODUCTION}

La technique du préfanage tend actuellement à se répandre dans la pratique de l'ensilage. Elle consiste à élever le taux de matière sèche du fourrage coupé en le laissant se faner partiellement sur le champ avant de l'ensiler. Elle présente aux yeux des utilisateurs l'avantage d'éviter l'addition d'agents de conservation, 
tout en constituant une garantie de réussite. Ainsi Dijkstra et Brandsma (I955), NASH (I959), MuRdoch (I960) et ZELTER (I960) ont observé que l'élévation du taux de matière sèche entraîne une réduction des pertes de matière organique et une amélioration de la qualité de l'ensilage par réduction des teneurs en azote ammoniacal et en acide butyrique. Toutefois, le $\mathrm{pH}$ acide (voisin de 4 ) habituellement utilisé comme critère de bonne qualité ne peut l'être ici en raison de ses valeurs élevées et les taux d'acide lactique observés en fin de conservation paraissent souvent faibles en regard de la qualité obtenue. L'ensemble de ces constatations amène à penser que le déroulement des fermentations est, dans les fourrages préfanés, différent de celui des ensilages humides. Or, pour utiliser au mieux la technique du préfanage, il est nécessaire de connaître les modifications apportées par l'élévation du taux de matière sèche à l'évolution des phénomènes biochimiques et bactériologiques; il serait alors possible de déterminer la concentration optimum de matière sèche qui oriente les phénomènes fermentaires dans le sens le plus favorable à la qualité du produit final.

Les études bactériologiques effectuées jusqu'ici sur ce type d'ensilage sont très incomplètes. Quelques observations ont été faites par STIRLING (I95I), sur des graminées ensilées en tubes durant quatorze jours ; un nombre limité de dénombrements ne comparant qu'un seul ensilage préfané au témoin a permis de noter un retard de la multiplication bactérienne au cours des cinq premiers jours, ainsi qu'une légère diminution de la microflore totale (la microflore anaérobie n'a pas été dénombrée). Une étude de ORTH (Ig60), également limitée à un seul ensilage préfané semble confirmer ces observations et montre en outre au sein de la microflore totale une proportion plus importante de bactéries lactiques. MInIN (I940), puis WIERINGA (I958) expliquent l'origine de l'inhibition de la germination des spores de Clostridium par l'augmentation de la pression osmotique due au préfanage ; cependant cette thèse demande à être confirmée. Finfin, aucune recherche n'a été effectuée sur les séquences d'apparition et les proportions relatives des espèces de streptocoques et de lactobacilles au cours de la conservation. Il semble pourtant d'après les travaux de IAATGSTON et BOUMA (I960 a), réalisés sur des ensilages humides que cet aspect qualitatif de la microflore lactique, susceptible de variations assez importantes soit en relation avec la qualité de l'ensilage.

Il ressort de ces travaux que les recherches bactériologiques menées dans la plupart des cas sans appui biochimique ont apporté des informations limitées. Nous avons entrepris d'approfondir ces deux aspects en étudiant l'influence de l'augmentation progressive du taux de matière sèche (M.S.) de la luzerne (I9,9 à 39,2 p. roo) sur l'évolution des processus fermentaires et de tenter d'en dégager le mécanisme d'action.

\section{MATÉRIEL ET TRAITEMENTS}

Une parcelle de luzerne, Medicago sativa, de type Poitou, de $2^{\mathrm{e}}$ coupe, au stade de ro p. roo de floraison constitue le matériel expérimental. Elle est divisée en cinq lots, puis fauchée le 27 juin I96I à $7 \mathrm{~h}$. Une partie aliquote de chaque lot est récoltée pour être ensilée aussitôt après la coupe puis après $3,5,7$ et 9 heures de préfanage par temps ensoleillé et chaud. Les taux de matière sèche atteints au moment de la mise en silo et la composition du fourrage sont indiqués dans le tableau $\mathbf{r}$. Le fourrage récolté est aussitôt haché court $(4-5 \mathrm{~cm})$, pesé et ensilé dans des silos cn grès étanches, drainés, d’une capacité de $50 \mathrm{dm}^{3}$. Le tassement est réalisé par piétinement et une pression de 
$700 \mathrm{~kg} / \mathrm{m}^{2}$ est maintenue tout au long de la conservation. Chaque traitement comporte trois répétitions et un échantillon moyen du fourrage est prélevé pour chaque groupe à la mise en silo.

Au cours de la conservation, des prélèvements verticaux sont effectués aseptiquement sur toute la profondeur du silo à l'aide d'une sonde cylindrique de $25 \mathrm{~mm}$ de diamètre, et les orifices sont immédiatement colmatés par des boyaux en polyvinyle remplis d'eau. Les prélèvements réalisés sur chacun des trois silos d'un mème groupe sont mélangés pour servir d'échantillons destinés aux anayses; ils ont lieu les $3^{\mathrm{e}}, 5^{\mathrm{e}}, 8 \mathrm{e}, 10^{\mathrm{e}}, 12^{\mathrm{e}}, 15^{\mathrm{e}}, 22^{\mathrm{e}}, 30^{\mathrm{e}}, 44^{\mathrm{e}}$ et $9^{8 \mathrm{e}}$ jours après la mise en silo.

\section{MÉTHODES EXPÉRIMENTALES}

\section{. Mesures biochimiques}

\section{Critères.}

Les critères retenus comportent, outre le plI :

- les concentrations en acide lactique et acides gras volatils;

- les taux d'azote non protéique, d'acides aminés et amides libres et d'azote ammoniacal.

\section{Techniques analytiques.}

I.es dosages sont effectués sur les échantillons conservés par congélation à - $20^{\circ} \mathrm{C}$.

Les sucres sont extraits à l'eau selon JARRIGE (I96I) et dosés par la méthode de Somogyi (I952). Le pH, la matière seche, les acides gras volatils, l'acide lactique, diverses formes azotées ( $N$ non protéique et $\mathrm{N}-\mathrm{NH}_{3}$ ) sont dosés par des méthodes déjà indiquées (ZELTER et SALOMON, r959). La technique d'extraction des formes azotées solubles est ainsi modifiée : après la cytolyse à l'éther, le résidu est broyé avec de l'eau distillée au lieu d'alcool à 80 p. Ioo.

Les acides aminés et amides libres sont déterminés sur l'extrait déféqué par de l'acide acétique et dessalifié sur colonne d'AMBERLITE IRI 20 ( I6 - 50 mesh). L'éluat ammoniacal est évaporé et chromatographié avec un système de solvants comprenant du méthyl-éthyl-cétone en descendant et du méthanol-pyridine en ascendant (BOLRDET et IIÉRARD, I958). Cette méthode permet d'évaluer avec une précision satisfaisante l' $\alpha$ alanine, la thréonine, les leucines (isoleucine et leucine), la valine, les acides $\alpha$ aminobutyrique, $\gamma$ aminobutyrique, et glutamique, la phénylalanine et l'asparagine. Les acides aminés basiques ne se séparant pas correctement entre eux, seule leur présence ou leur absence peut être relevée.

\section{Critères.}

\section{Examens bactiriologiques}

Les critères bactériologiques portent sur :

le dénombrement des microflores totale, Gram positive et anaérobie sporulée, l'identification des souches représentatives de la microflore Gram positive.

\section{Techniques analytiques ${ }^{1}$ ).}

Les dénombrements des différentes microflores sont réalisés sur les milieux suivants :

- la microflore totale, sur milieu gélosé A de Elliker, INDERSON et IIANNisSON (I956) ;

- la microflore Gram positive, sur milieu gélosé sélectif B préparé par addition au milieu A de 0,05 p. I00 d'acétate de thallium et 0,05 p. I00 de chlorure de triphényl tétrazolium (SHARPE, I955);

- les lactobacilles, sur milieu gélosé sélectif C de DE Mas, Rogosa et SHarpe (I960) ;

- les sporulés anaérobies, sur les deux milieux de RosenbERGER (I95I). B et $\mathrm{C}$.

A chaque prélèvement, des souches de lactobacilles et de coques ont été isolées des milieux

\section{RÉSULTATS}

Quel que soit le taux de matière sèche, nous n'avons à aucun moment relevé d'écoulement de jus.

(1) Le détail des techniques analytiques sera prochainement publié aux Annales de l'Institut Pasteur. 


\section{RÉSULTATS BIOCHIMIQUES}

\section{Evolution de la composition de la luzerne en fonction de la durée du préfanage}

Les modifications dans la composition initiale de la luzerne au cours du préfanage sur le champ sont progressives (tabl. I). Elles atteignent leur maximum après $7 \mathrm{~h}$ de préfanage. Le taux de sucres totaux s'accroît alors de $7^{2}$ p. Ioo, celui

TABLEAU I

Composition de la luzerne à la mise en silo

\begin{tabular}{c|c|c|c|c|c}
\hline \hline Traitement & $\begin{array}{c}\text { Durée } \\
\text { de préfanage } \\
\text { en heures }\end{array}$ & $\begin{array}{c}\text { Matière sèche } \\
\text { en \% } \\
\text { du produit brut }\end{array}$ & $\begin{array}{c}\text { Composition en \% de la matière sèche (M. S.) } \\
\text { Sucres totaux }\end{array}$ & Ifémicelluloses & Azote total \\
Témoin T & 0 & 19,9 & 2,48 & 10,45 & 3,79 \\
I & 3 & 25,2 & 2,33 & 10,22 & 4,04 \\
II & 5 & 31,7 & 3,67 & 10,34 & 3,71 \\
III & 7 & 35,8 & 4,27 & 9,23 & 3,60 \\
IV & 9 & 39,2 & 3,85 & 8,72 & 3,79 \\
\hline
\end{tabular}

des « hémicelluloses " s'abaisse de II p. Ioo (il s'agit ici de l'ensemble des polysaccharides extraits par $\mathrm{SO}_{4} \mathrm{H}_{2} 5 \mathrm{p}$. Ioo et mesurés par le pouvoir réducteur de 1'hydrolysat $(X 0,9)$ ). Dans le même temps, les teneurs en $\mathrm{N}$ non protéique et en $\mathrm{N}$ ammoniacal s'accroissent respectivement de 40 et $5_{50}$ p. Ioo (fig. I). Certains acides aminés sont libérés (fig. I), en particulier l'acide $\gamma$ aminobutyrique qui augmente sensiblement alors que le taux initial d'asparagine triple (fig. I).
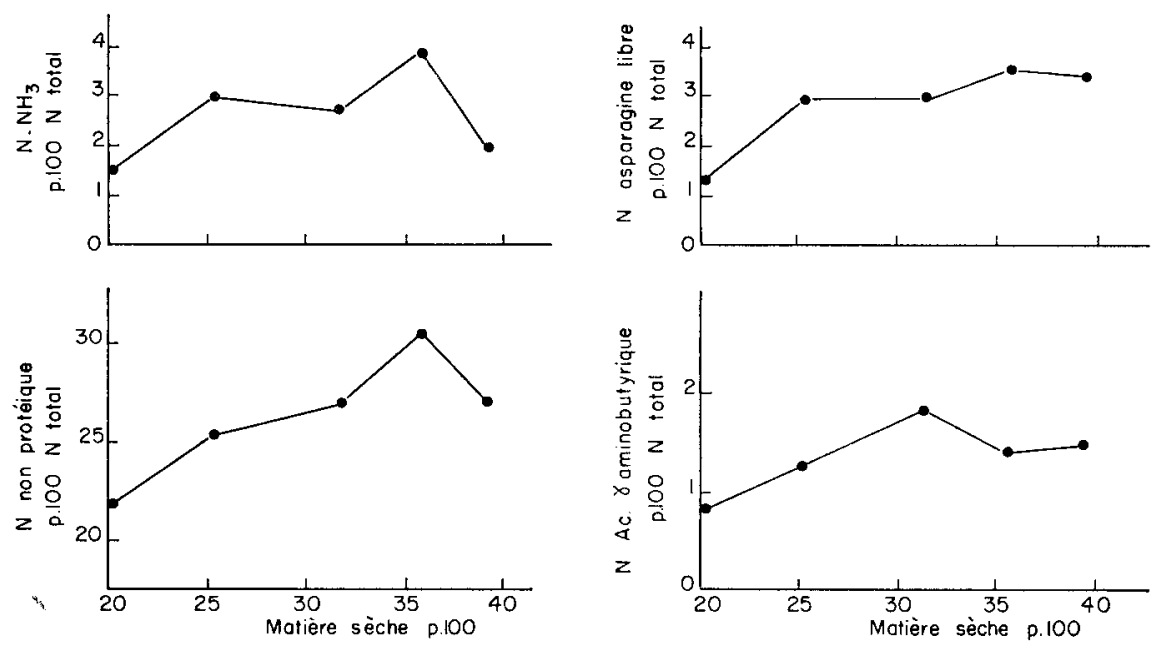

FIG. I. - Évolution de certaines fractions azotées au cours du préfanage 


\section{Évolution des phénomènes fermentaires au cours de la conservation}

Dans l'ensilage témoin (non préfané : r9,9 p. roo MI.S.), le pH (fig. 2), initialement de 6,4 passe à 5,5 au $3^{\mathrm{e}}$ jour; il se maintient autour de cette valeur jusqu'au $44^{\mathrm{e}}$ jour pour s'élever ensuite. Dans les ensilages les plus préfanés $(35,8$ et 39,2 p. Ioo de M.S.), il reste à son niveau initial jusqu'au $30^{\mathrm{e}}$ jour pour s'abaisser ensuite à 5,2 .

\section{Phénomènes glycolytiques (fig. 2)}

Acide lactique.

Sa production dans le témoin est massive dès les 3 premiers jours ; elle atteint son maximum au $30^{\mathrm{e}}$ jour ; cet acide est dégradé très rapidement par la suite.
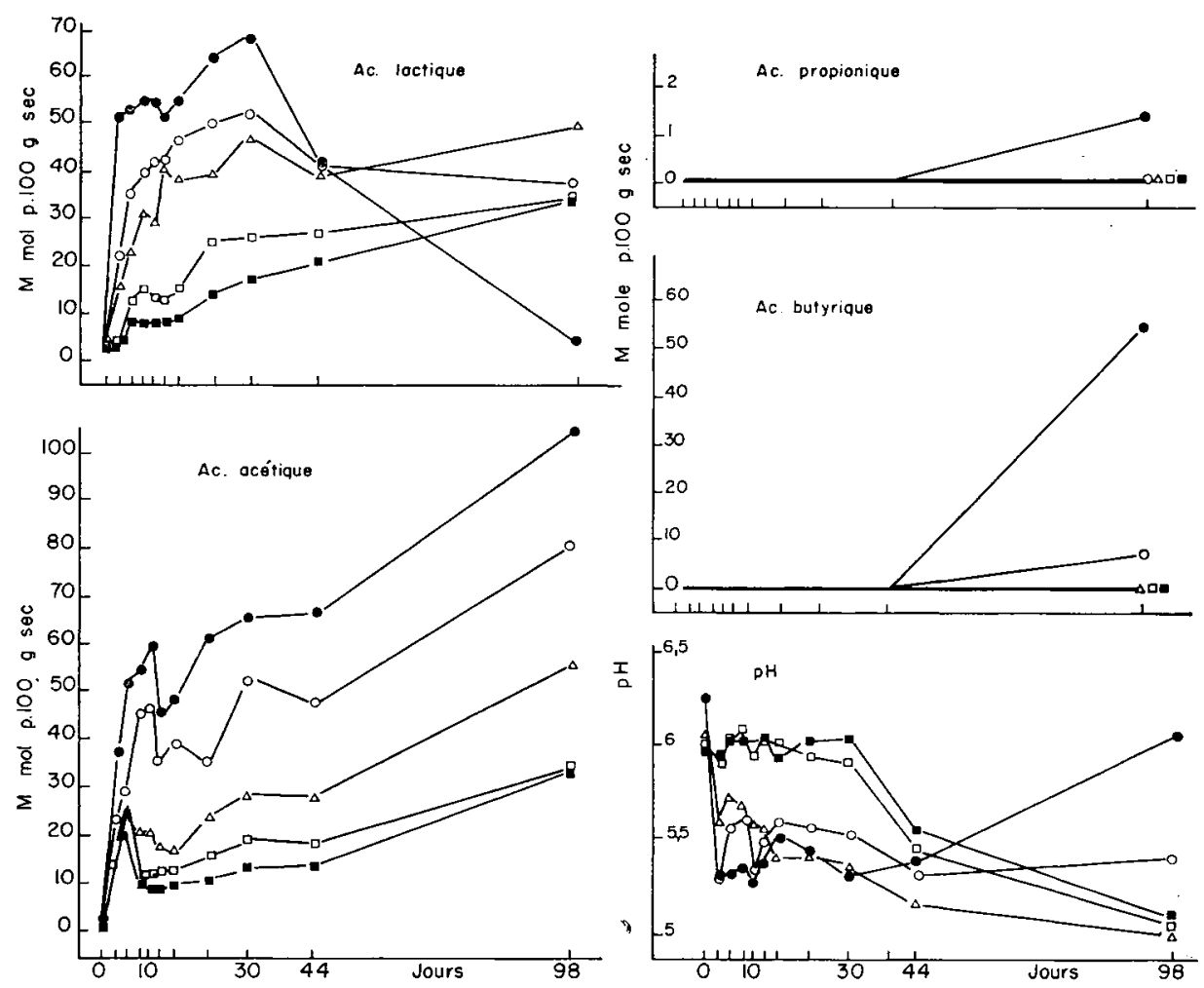

Fig. 2. - Influence du taux de matière sèche sur le pH et l'évolution des teneurs en acide lactique et acides gras volatils au cours de la conservation

L'accroissement du taux de matière sèche retarde le démarrage de la fermentation lactique et réduit son intensité. Au delà du taux de 30 p. Ioo de M.S., l'acide lactique s'accumule dans le milieu jusqu'en fin de conservation. 


\section{Acide acétique.}

Dans tous les ensilages, la concentration en acide acétique s'élève rapidement dans les 5 premiers jours; elle s'abaisse ensuite entre le $5^{\mathrm{e}}$ et $1 \mathrm{le} 5^{\mathrm{e}}$ jour suivant le traitement. La production de cet acide reprend progressivement ensuite. Mais à tout moment, les concentrations sont d'autant plus faibles que le milieu est plus riche en M.S. Au $9^{8 \mathrm{e}}$ jour, il y a 3 fois moins d'acide acétique dans l'ensilage IV (M.S. 39,2 p. IOO) que dans le témoin.

Acide propionique.

Seul le témoin en contient de faibles quantités en fin de conservation.

\section{Acide butyrique.}

Il apparâ̂t après le $44^{\mathrm{e}}$ jour en quantité importante dans le témoin et très faible dans l'ensilage le moins préfané (M.S. 25,2 p. I00). Les ensilages plus préfanés n'en contiennent pas.

\section{Phénomènes protéolytiques}

Dans tous les ensilages, l'hydrolyse des protéines suit sensiblement la même évolution comme en témoigne la progression des taux d'azote non protéique (fig. 3). Les trois quarts de l'azote non protéique apparu pendant la conservation sont déjà présents au $5^{\mathrm{e}}$ jour. La protéolyse se stabilise à partir du $44^{\mathrm{e}}$ jour. L'élévation de

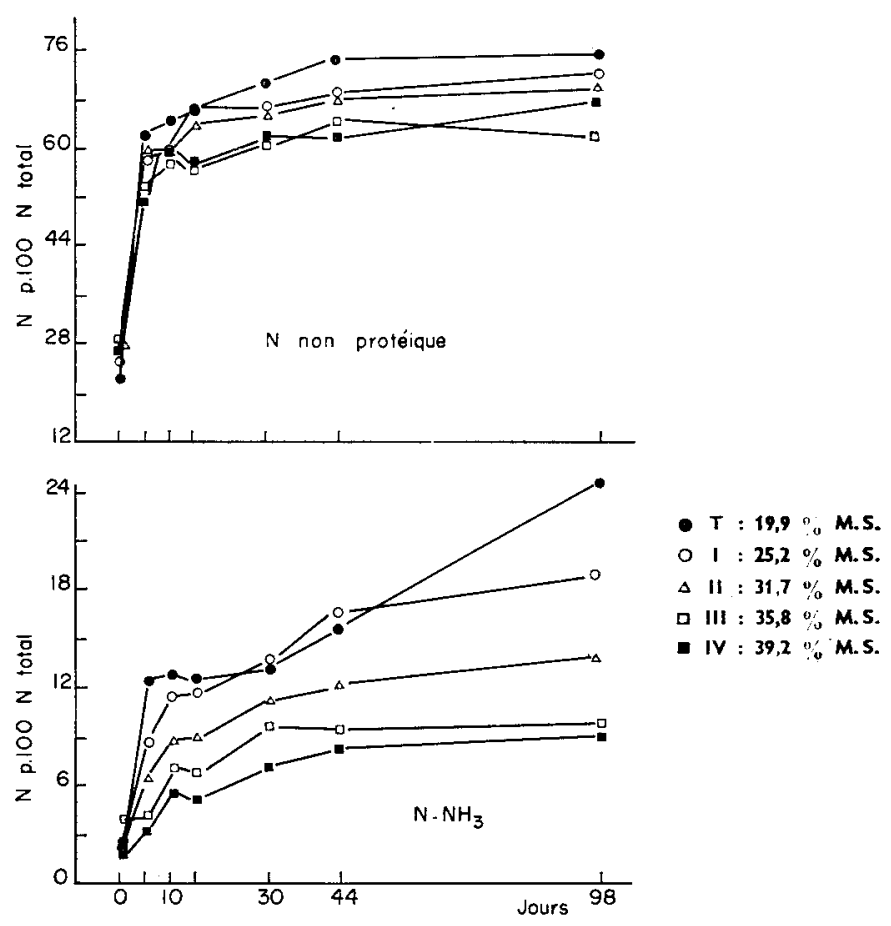

FIG. 3. - Influence du taux de matière sèche sur l'évolution de la protéolyse au cours de la conservation 


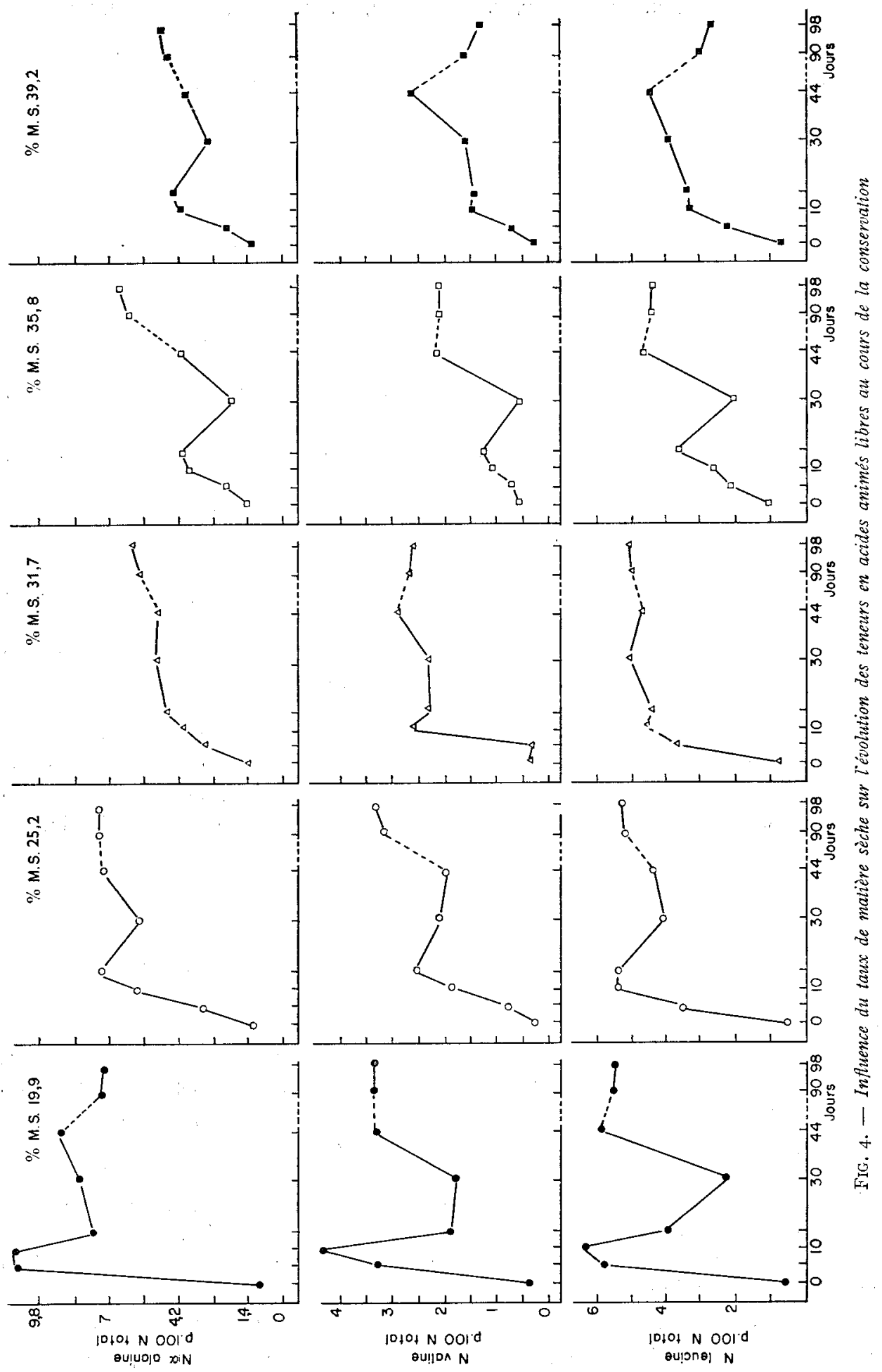


la matière sèche atténue ce processus dès le départ et tout au long de la conservation. $\mathrm{Au} 9^{8 \mathrm{e}}$ jour, les taux d'azote non protéique des ensilages les plus préfanés (M.S. : 35,8 et 39,2 p. Ioo) sont respectivement inférieurs de I8 et Io p. Ioo à celui du témoin.

\section{Acides aminés et amides libres (fig. 4-5-6).}

Dans le témoin, les concentrations en $\alpha$ alanine, acide $\alpha$ aminobutyrique, $\gamma$ aminobutyrique, leucines, valine et phénylalanine subissent des fluctuations importantes: elles s'élèvent fortement dans les ro premiers jours, s'abaissent vers le $15^{\mathrm{e}}$ jour pour augmenter de nouveau après I mois. La thréonine et l'acide glutamique libérés au $8 \mathrm{e}$ jour ont presque entièrement disparu au $\mathrm{IO}^{\mathrm{e}}$, et l'asparagine en totalité. Les acides aminés basiques disparaissent totalement après I mois de conservation. En général, les processus de libération et de disparition des acides aminés et amides libres sont d'autant plus retardés et plus réduits que le taux de M.S. est plus élevé. En particulier, à partir de $25 \mathrm{p}$. Ioo de matière sèche, les acides aminés basiques sont présents jusqu'au $9^{8 \mathrm{e}}$ jour. $\mathrm{A}$ partir du taux de $30 \mathrm{p}$. Ioo de matière sèche, il se forme de l'asparagine après le $30^{\mathrm{e}}$ jour.

Ammoniogenèse (fig. 3).

L'inhibition de l'ammoniogenèse est directement en rapport avec l'intensité dut préfanage.

Dans le témoin, la formation d'ammoniaque (fig. 3) est particulièrement intense dans les 5 premiers jours : sa concentration représente alors déjà la moitié de la valeur finale. Elle reprend ultérieurement (après I mois) et se poursuit jusqu'à la fin de la conservation, alors que pour les ensilages III $(35,8$ p. Ioo de M.S.) et IV $(39,2$ p. Ioo de $M$. S.), elle est pratiquement terminée au $30^{e}$ jour. En fin de conservation, les concentrations en azote ammoniacal de ces ensilages préfanés ne représentent que I5,8 et I3,3 p. Ioo de l'azote non protéique contre $32 \mathrm{p}$. Ioo pour le témoin.

\section{RÉSULTATS BACTÉRIOLOGIQUES}

\section{Aspect quantitatif de la cinétique du développement bactérien}

\section{Microflores totale et Gram positive.}

I a microflore totale (tabl. 2) dénombrée sur le miliet $A$ correspond approximativement à l'ensemble de la microflore aérobie stricte et facultative. La microflore Gram positive (tab1. 3) comprend des streptocoques, des pédiocoques, et des lactobacilles. L'importance numérique de ces deux microflores au moment de la coupe est minime, particulièrement pour la seconde. Alors que la microflore totale diminue constamment au cours du préfanage, la microflore Gram positive augmente au cours des cinq premières heures pour diminuer nettement par la suite.

L'élévation du taux de matière sèche par préfanage $a$, durant la conservation en silo, pour conséquences :

- de ralentir le taux de croissance bactérienne. La phase de croissance maximale, encadrée dans les tableaux 2 et 3 (intervalle de temps des trois prélèvements 


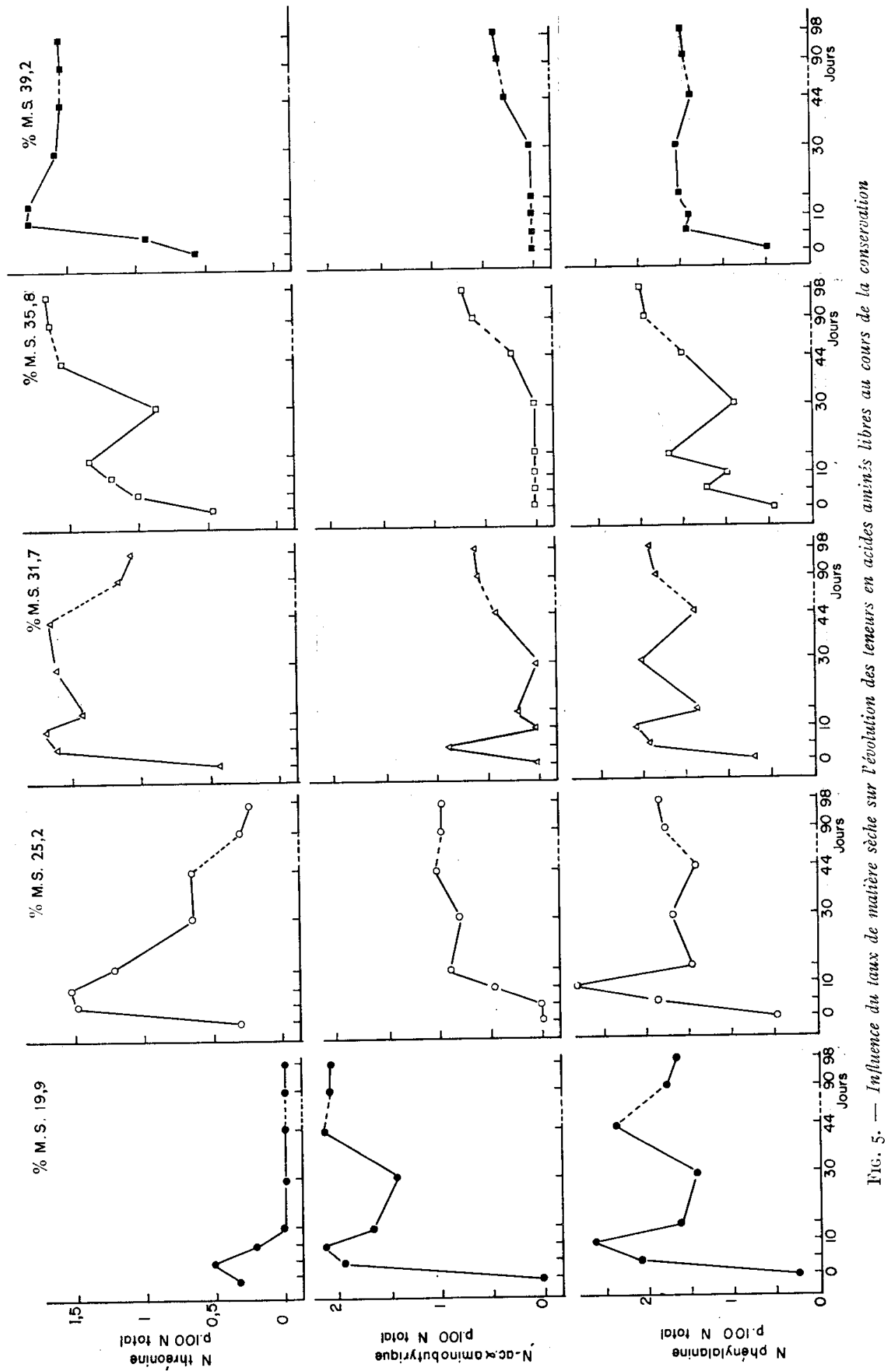




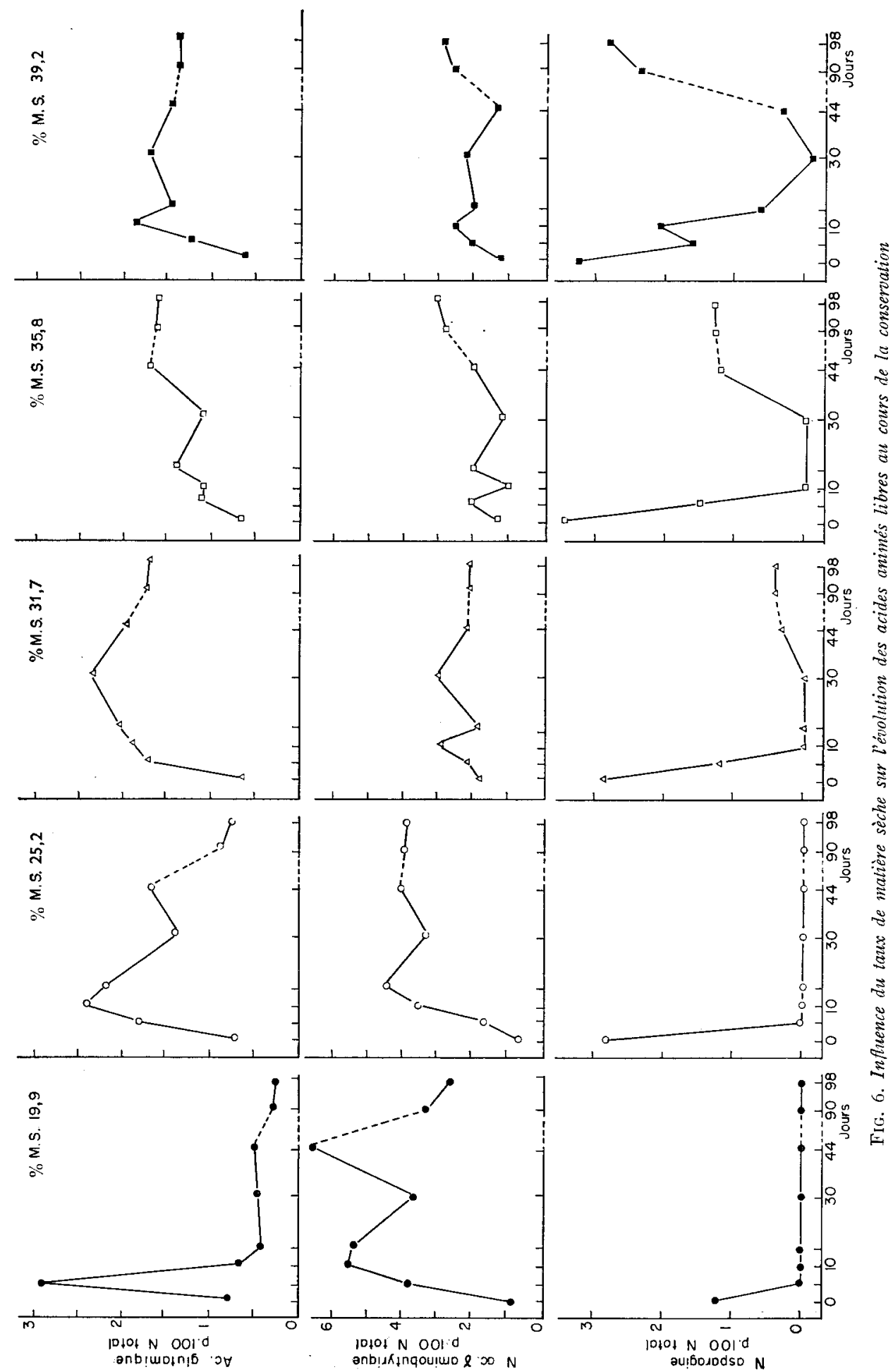


PRÉFANAGE PROGRESSIF ET ÉVOLUTION DE L'ENSILAGE

consécutifs ayant donné les dénombrements les plus élevés) apparaît de plus en plus tardivement :

- de diminuer le taux moven de décroissance bactérienne (calculée par diffé-

TABLEAU 2

Évolution quantitative de la microflore totale dans les différents ensilages

(en millions par g de M.S.).

\begin{tabular}{|c|c|c|c|c|c|}
\hline Jours & $\mathrm{T}$ & I & II & III & IV \\
\hline 1 & $t_{1} 6$ & 10 & 11 & 16 & 6 \\
\hline$: 3$ & 985 & 78.3 & 566 & 139 & 89 \\
\hline 5 & 3300 & 1725 & 577 & 472 & 991 \\
\hline 8 & $371 / \mathrm{t}$ & $137^{\prime} t$ & $1 / 71$ & 773 & 378 \\
\hline 10 & $201 t^{\prime}$ & $\geq 329$ & 1180 & 517 & 383 \\
\hline 12 & $199^{\prime}$ & 1023 & 1468 & 557 & 372 \\
\hline 15 & $7 \div 6$ & 577 & 1131. & $133^{\prime} 6$ & 302 \\
\hline 20 & 2250 & $1: 16$ & 1086 & 1023 & 498 \\
\hline 30 & 990 & 720 & 890 & 699 & 1417 \\
\hline 4't & 777 & 657 & 337 & 465 & 189 \\
\hline 98 & 310 & $\geq 10$ & 位' & 237 & 397 \\
\hline Moyenne des 3 nombres & & & & & \\
\hline $\operatorname{maxima} \ldots \ldots \ldots \ldots$ & 3009 & 1809 & 1373 & 189 & 739 \\
\hline Moyenne du total ...... & $170^{\prime}$ & 1081 & 916 & 613 & 1205 \\
\hline Différence entre 3 max. - & & & & & \\
\hline dernier $\ldots \ldots \ldots \ldots \ldots$ & 2694 & 1590 & 919 & 752 & 3192 \\
\hline
\end{tabular}

TABLEAU 3

Évolution quantitative de la microflore Gram positive dans les différents ensilages (en millions par g de M.S.)

\begin{tabular}{|c|c|c|c|c|c|}
\hline Jours & $\mathrm{T}$ & I & II & III & IV \\
\hline 0 & 0,3 & 0.6 & \multirow{4}{*}{$\begin{array}{l}0.6 \\
398 \\
587 \\
721\end{array}$} & 0,05 & 0,02 \\
\hline 3 & $51: ;$ & 76 & & 78 & 28 \\
\hline 5 & 1840 & 925 & & 200 & 272 \\
\hline 8 & 1481 & 1496 & & 353 & 172 \\
\hline 10 & 2961 & 1580 & \multirow{3}{*}{$\begin{array}{ll}1 & 6065 \\
1 & 066^{\prime} \\
1010\end{array}$} & 357 & \multirow{4}{*}{$\begin{array}{l}180 \\
235 \\
35 ! \\
541 \\
\end{array}$} \\
\hline 12 & $131: 3$ & 711 & & \multirow{3}{*}{$\begin{array}{l}818 \\
68^{\prime} \\
41 ' t \\
\end{array}$} & \\
\hline 15 & 494 & 569 & & & \\
\hline 22 & 871 & 852 & 687 & & \\
\hline 30 & 661 & 695 & 569 & 479 & \multirow{3}{*}{$\begin{array}{l}915 \\
495 \\
590\end{array}$} \\
\hline 44 & $41 j$ & $30: 1$ & 235 & 465 & \\
\hline 98 & 111 & 110 & 107 & 318 & \\
\hline \multirow{3}{*}{$\begin{array}{l}\text { Moyenne des } 3 \text { nombres } \\
\text { maxima } \ldots \ldots \ldots \ldots \ldots \\
\text { Moyenne du total } \ldots \ldots \ldots\end{array}$} & & & & & \multirow{4}{*}{$\begin{array}{l}666 \\
378\end{array}$} \\
\hline & 1928 & 1335 & 1296 & 639 & \\
\hline & 994 & 733 & 699 & 417 & \\
\hline 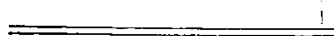 & & & & & \\
\hline
\end{tabular}


rence entre la moyenne des trois nombres consécutifs maxima observés et le nombre du dernier prélèvement (tabl. 2);

- de réduire l'écart entre les valeurs moyennes des microflores totale et Gram positive dans des proprotions de I à $\mathrm{I}_{5}$ (fig. 7 ).

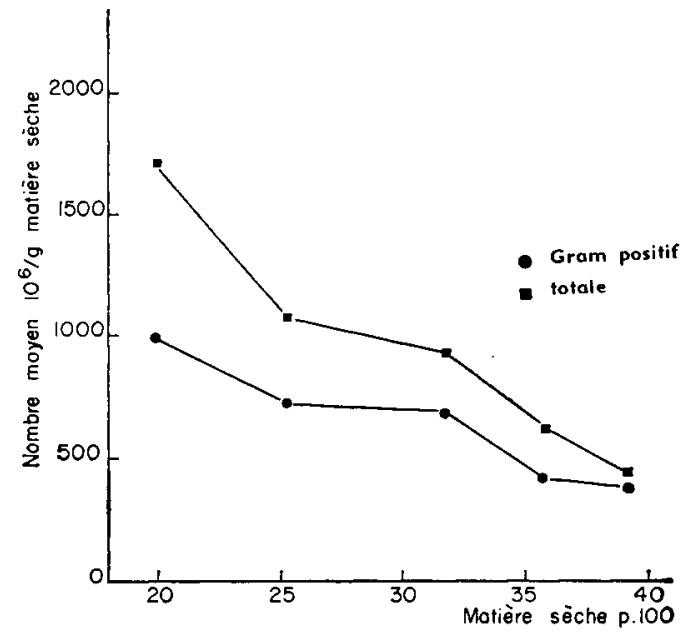

Fig. 7. Évolution en fontion du taux de matière sèche des écarts entre les microfores totale et gram positive

\section{Les lactobacilles.}

L'évolution générale est celle constatée pour les microflores totale et Gram positive ; lorsque le taux de matière sèche s'élève, le nombre des lactobacilles diminue (tabl. 4).

\section{TABLEAU 4}

Évolution quantitative des lactobacilles au cours de la fermentation (en millions par g de M.S.)

\begin{tabular}{|c|c|c|c|c|c|}
\hline Jours & $\mathrm{T}$ & $\mathrm{I}$ & II & III & IV \\
\hline 0 & 0,10 & 0,02 & 0,017 & 0,002 & 0,0005 \\
\hline 3 & 15 & 613 & 388 & 82 & 36 \\
\hline 5 & 3450 & 1215 & $53{ }^{2}{ }_{t}$ & 147 & 205 \\
\hline 8 & 4476 & $1 f^{\prime} 6^{\prime}$ & 1170 & 403 & $2: 1$ \\
\hline 10 & 2881 & $1 \times 57$ & 1409 & 189 & 245 \\
\hline 12 & 1243 & 797 & 1019 & 501 & 235 \\
\hline 15 & 1386 & 1271 & 800 & 577 & $61 / 4$ \\
\hline 22 & $79 \prime$ & $7: 2$ & 1116 & 846 & 203 \\
\hline 30 & 1124 & 71 & 1065 & 538 & 555 \\
\hline 'í & 812 & 493 & 305 & 416 & $23 /$ \\
\hline 98 & 1005 & $45: 3$ & 181 & 150 & 151 \\
\hline Moyenne des 3 noinbres & & & & & \\
\hline maxima $\ldots \ldots \ldots \ldots$ & 3602 & 1522 & 1199 & 611 & 457 \\
\hline Moyenne du total ....... & 1870 & 971 & 799 & 418 & 272 \\
\hline
\end{tabular}


Les anaérobies sporulés.

L'importance de cette microflore négligeable jusqu'au $3^{\mathbf{e}}$ jour, devient très marquée dans l'ensilage témoin et particulièrement pour les Clostridia fermentant le lactate (tab1. 5) qui doublent entre le $30^{\mathrm{e}}$ et le $44^{\mathrm{e}}$ jour et décuplent du $44^{\mathrm{e}}$ au 98 jour.

Dans l'ensilage le moins préfané (25 p. Ioo de M.S.), le maximum atteint est voisin de $I 0^{5} / g$ de M.S. ; dans les autres, par contre, il atteint à peine quelques milliers.

I.es résultats du dénombrement des Clostridia protéolytiques sont assez fluctuants mais sensiblement plus élevés que les précédents. Ils augmentent nettement dans le témoin après le $22^{\mathrm{e}}$ jour.

\section{TABIEAU 5}

Évolulion des anaérobies sporulés du $22^{\mathrm{e}}$ au $9^{\mathrm{e}}$ jour

(en milliers par $\mathrm{g}$ de M.S.)

\begin{tabular}{|c|c|c|c|c|c|}
\hline \multirow[b]{2}{*}{ Traitement } & \multirow{2}{*}{$\begin{array}{c}\text { Jour } \\
\text { de prélèvemnent }\end{array}$} & \multicolumn{2}{|c|}{ Milieu au lactate } & \multicolumn{2}{|c|}{ Milieu à la gélatine } \\
\hline & & non chauffés & $\begin{array}{c}\text { chauffés } 10 \mathrm{mn} \\
75^{\circ} \mathrm{C}\end{array}$ & non chauffés & $\begin{array}{c}\text { chauffés } 10 \mathrm{mn} \\
75 \circ \mathrm{C}\end{array}$ \\
\hline $\mathrm{T}$ & $\begin{array}{l}2 \cdot 2 \\
30 \\
4 \cdot 4 \\
98\end{array}$ & $\begin{array}{r}72 \\
120 \\
110 \\
2400\end{array}$ & $\begin{array}{r}10 \\
220 \\
520 \\
5100\end{array}$ & $\begin{array}{r}10 \\
220 \\
620 \\
510\end{array}$ & $\begin{array}{r}10 \\
370 \\
110 \\
810\end{array}$ \\
\hline I & $\begin{array}{l}29 \\
30 \\
44 \\
98\end{array}$ & $\begin{array}{r}60 \\
67 \\
34 \\
100\end{array}$ & $\begin{array}{l}10 \\
101 \\
91 \\
10\end{array}$ & $\begin{array}{r}10 \\
100 \\
1600 \\
10\end{array}$ & $\begin{array}{r}200 \\
200 \\
310 \\
39\end{array}$ \\
\hline II & $\begin{array}{l}22 \\
30 \\
44_{4} \\
98\end{array}$ & $\begin{array}{l}0,340 \\
0,8 \div 0 \\
0,7 \geq 6 \\
8,4\end{array}$ & $\begin{array}{l}0,520 \\
0,820 \\
0,262 \\
0,8,0\end{array}$ & $\begin{array}{l}10 \\
15 \\
27 \\
15\end{array}$ & $\begin{array}{l}10 \\
15 \\
13 \\
15\end{array}$ \\
\hline III & $\begin{array}{l}22 \\
30 \\
44 \\
98\end{array}$ & $\begin{array}{l}0,155 \\
0,276 \\
0,024 \\
1,3\end{array}$ & $\begin{array}{l}0,200 \\
0,276 \\
0,107 \\
0,130\end{array}$ & $\begin{array}{l}1 \\
7,2 \\
6,7 \\
2,8\end{array}$ & $\begin{array}{l}7,2 \\
7,2 \\
6,7 \\
0,722\end{array}$ \\
\hline IV & $\begin{array}{l}22 \\
30 \\
4 ! \\
98\end{array}$ & $\begin{array}{l}0,425 \\
0,690 \\
0,622 \\
0,066\end{array}$ & $\begin{array}{l}0,325 \\
0,686 \\
0,22 ' t \\
0,066\end{array}$ & $\begin{array}{l}0,490 \\
0,690 \\
0,230 \\
0,066\end{array}$ & $\begin{array}{l}0,590 \\
0,690 \\
0,197 \\
0,251\end{array}$ \\
\hline
\end{tabular}

Aspect qualitatif de la cinétique du développement de la microflore Gram positive.

Proportions de lactobacilles et de coques en fonction du taux de matière sèche et de la phase fermentaire.

Durant la phase de croissance de la microflore Gram positive dont la durée varie suivant le traitement, la proportion de lactobacilles est réduite par l'élévation 
du taux de matière sèche : elle passe de 67 p. Ioo pour le témoin à 42 p. Ioo pour l'ensilage le plus préfané (tab1. 6). Cet effet du préfanage se retrouve aussi pendant.

TABLEAU 6

Proportions de lactobacilles et de coques dans la microflore $G+{ }^{(1)}$

\begin{tabular}{|c|c|c|c|c|c|c|c|c|}
\hline \multirow{3}{*}{ Traitement } & \multicolumn{5}{|c|}{ Pendant la phase de croissance } & \multicolumn{3}{|c|}{$\begin{array}{l}\text { Pendant la durcé totale } \\
\text { de la conservation }\end{array}$} \\
\hline & \multirow{2}{*}{$\begin{array}{c}\text { Phase } \\
\text { d'isolement } \\
\text { en jours (2) }\end{array}$} & \multicolumn{2}{|c|}{ Lactobacilles } & \multicolumn{2}{|c|}{ Coques } & \multirow{2}{*}{$\begin{array}{l}\mathrm{G+} \\
\text { Total isolé } \\
\text { pendant } \\
98 \text { jours }\end{array}$} & \multirow{2}{*}{$\begin{array}{l}\text { Lacto- } \\
\text { bacilles } \\
\% \text { total } \\
\mathrm{i}+\end{array}$} & \multirow{2}{*}{$\begin{array}{c}\text { Coques } \\
\% \text { total } \\
\mathrm{G}+\end{array}$} \\
\hline & & $\begin{array}{l}\text { Souches } \\
\text { isolées }\end{array}$ & $\begin{array}{l}\% \text { micro- } \\
\text { fore } G+\end{array}$ & $\begin{array}{l}\text { Souches } \\
\text { isolées }\end{array}$ & $\begin{array}{l}\% \text { micro- } \\
\text { flore } G+\end{array}$ & & & \\
\hline $\mathrm{T}$ & $1-s$ & 32 & 67 & 16 & 33 & 118 & 78 & 22 \\
\hline I & $1-8$ & 23 & 50 & 23 & 50 & 116 & 57 & 43 \\
\hline II & $1-13$ & $3:$ & $5^{\prime}$ & 27 & 46 & 111 & 69 & 31 \\
\hline III & $1-15$ & 26 & 42 & 19 & 58 & 113 & 55 & 45 \\
\hline IV & 1 一 & 39 & 42 & 15 & 58 & $10^{\prime}$ & 48 & 52 \\
\hline
\end{tabular}

(1) $\mathrm{G}+=$ Gram positif.

${ }^{2}$ Les périodes correspondent aux phases de croissance bactírienne dans chaque ensilage.

toute la durée de la fermentation divisée en 3 séquences pour simplifier l'exposé des résultats (tabl. 7 ) : la population Gram positive finale $\left(44^{\mathrm{e}}\right.$ au $9^{8 \mathrm{e}}$ jour) comporte $93 \mathrm{p}$. Ioo de lactobacilles dans le témoin contre 65 p. Ioo seulement dans l'ensilage IV, les coques représentant le reste.

TABIEAU 7

Proportion des lactobacilles au cours de différentes périodes

(en p. Ioo du nombre de souches Gram positives isolées de B par traitement)

\begin{tabular}{|c|c|c|c|c|c|c|}
\hline \multirow{3}{*}{$\begin{array}{l}\text { Périodes en jours } \\
\text { Traitement }\end{array}$} & \multicolumn{2}{|c|}{$y^{e}$ an $8^{e}$} & \multicolumn{2}{|c|}{$10^{\mathrm{e}}$ au $30^{\mathrm{e}}$} & \multicolumn{2}{|c|}{$44^{\circ}$ au $98^{\mathrm{e}}$} \\
\hline & \multicolumn{6}{|c|}{ Nombre $\mathrm{N}$ de colonies $\mathrm{G}+$ isolées et $\%$ de lactobacilles } \\
\hline & $x$ & $\%$ & $\mathrm{~N}$ & $\%$ & $\mathrm{~N}$ & $\%$ \\
\hline $\mathrm{T}$ & 48 & 67 & 28 & 75 & 42 & 93 \\
\hline I & 46 & 50 & 29 & 52 & 41 & 68 \\
\hline II & 47 & 55 & 24 & 71 & 10 & 85 \\
\hline III & $t_{1}^{\prime}$ & 38 & 27 & 59 & 42 & 69 \\
\hline $\mathrm{II}^{-}$ & 4't & 29 & 29 & 59 & 31 & 65 \\
\hline
\end{tabular}

Par contre, en fonction de la durée de conservation pour chacun des traitements, on constate une augmentation de la proportion des lactobacilles. 
Proportions des différents genres ou espèces de bactéries Gram positives en fonction du taux de matière sèche et de la phase fermentaire.

Quel que soit le mode de calcul choisi (en p. Ioo de la microflore Gram positive dans le tableau 8 , de la totalité des lactobacilles ou des coques dans 9 et ro), l'élévation du taux de M.S. augmente les proportions de L. plantarum (tabl. $S$ et 9 ) et parti-

\section{TABLEAU 8}

Proportions des différents genres ou espèces de bactéries lactiques isolées

(En p. roo du nombre total de bactéries lactiques $\mathrm{G}+$ isolées de $\mathrm{B}$ dans chaque traitement)

\begin{tabular}{|c|c|c|c|c|c|c|c|c|}
\hline $\begin{array}{l}\text { Traite- } \\
\text { ments }\end{array}$ & $\begin{array}{l}\text { L. plan- } \\
\text { tamun }\end{array}$ & L. casei & $\begin{array}{l}\text { Lacto- } \\
\text { bacilles } \\
\text { hátéro- } \\
\text { fennen- } \\
\text { taires }\end{array}$ & $\begin{array}{c}\text { Lacto- } \\
\text { bacilles } \\
\text { ramifiés }\end{array}$ & Pédi ocoque & $\begin{array}{l}\text { Strepto- } \\
\text { coques }\end{array}$ & $\begin{array}{l}\text { Jenco- } \\
\text { nostor }\end{array}$ & $\begin{array}{c}\text { Non } \\
\text { identifiés }\end{array}$ \\
\hline $\mathrm{T}$ & 16,9 & $25, \mathbf{t}$ & 23,7 & 8,6 & (i,8 & $\{, \underline{z}$ & 5.9 & $\mathrm{~B}, \tilde{3}$ \\
\hline $\mathrm{I}$ & 19,8 & 21,5 & $9, \mathbf{1}$ & 1,3 & 10,3 & 10,7 & 7,7 & 1,3 \\
\hline II & 48,6 & 12,6 & $5, y^{\prime}$ & 2,7 & $1 ;, 3$ & $I^{\prime},{ }^{\prime}{ }^{\prime}$ & 8,1 & 1,9 \\
\hline III & 23 & 18,5 & 6,2 & 4 & 9,5 & 18,5 & 13,2 & 6,7 \\
\hline IV & 21,1 & 19,2 & 6,6 & 1 & 9,5 & 21,1 & 16,3 & 5,2 \\
\hline
\end{tabular}

TABLEAU 9

Eúolution des différentes espèces de lactobacilles en fonction du taux de matière sèche (En p. Ioo du nombre total des lactobacilles isolées de $\mathrm{B}$ et $\mathrm{C}$ par traitement).

\begin{tabular}{|c|c|c|c|c|c|c|c|}
\hline Traitements & $\begin{array}{c}\text { Taux } \\
\text { de M.S. } \\
\text { initial }\end{array}$ & $\begin{array}{l}\text { Nombre total } \\
\text { de souches } \\
\text { isolies }\end{array}$ & I. planlarm & I. a asel & $\begin{array}{l}\text { Lacto- } \\
\text { bacilles } \\
\text { hétćro- } \\
\text { fermen- } \\
\text { taires }\end{array}$ & $\begin{array}{l}\text { Iacto- } \\
\text { bacilles } \\
\text { "rumifiés " }\end{array}$ & $\begin{array}{c}\text { Non } \\
\text { idlentifiés }\end{array}$ \\
\hline $\mathrm{T}$ & 19,9 & 1,0 & 19,3 & 10,7 & 95,7 & 10,8 & $3, \overline{3}$ \\
\hline$I$ & 25,2 & 93 & $34, \mathbf{t}$ & 39,8 & 12,9 & 11,9 & 1 \\
\hline II & 31,7 & 101 & 72,3 & 15,8 & 13 & $\dot{1}$ & 1,9 \\
\hline III & 35,8 & 101 & 42,6 & 31,2 & $\bar{T}$ & 13,2 & 6 \\
\hline IV & 39,2 & 67 & $t_{1} 1,8$ & 41,8 & 12 & 't,'s & 0 \\
\hline
\end{tabular}

culièrement dans l'ensilage II, alors qu'elle diminue celle des lactobacilles hétérofermentaires. Le tableau II montre principalement que ces derniers ne se développent guère au cours de la phase de croissance dans les ensilages préfanés.

Parmi les streptocoques, on constate une augmentation des Str. faecalis et des Leuconostoc parallèlement à l'élévation du taux de matière sèche, alors que les pédiocoques régressent sensiblement (tabl. Io). Dans l'ensilage témoin nous notons une proportion assez importante de streptocoques non identifiés. 
PH. GOUET, N. FATIANOFF, S. Z. ZEITER, M. DURAND, R. CHEVALIER

TABLEAU IO

Évolution des différents genres ou espèces de coques en fonction du taux de matière sèche (en p. Ioo du nombre de coques isolés de B)

\begin{tabular}{|c|c|c|c|c|c|c|}
\hline Traitement & $\begin{array}{l}\text { Taus } \\
\text { de MI.S. } \\
\text { initial }\end{array}$ & $\begin{array}{l}\text { Nombre total } \\
\text { de souches } \\
\text { isolées }\end{array}$ & Pédiocoque & $\begin{array}{l}\text { Sir. faecalis } \\
\text { Sir. lique- } \\
\text { faciens }\end{array}$ & Leuconostoc & $\begin{array}{l}\text { Non } \\
\text { identifiés }\end{array}$ \\
\hline $\mathrm{T}$ & 19,8 & 26 & 30,8 & 19,2 & 26,9 & 23,1 \\
\hline I & 25,2 & 50 & $2{ }^{\prime}$ & 48 & 18 & 10 \\
\hline II & 31,7 & $3 \prime \mathbf{k}$ & 21,2 & 48,5 & 24,2 & 3 \\
\hline III & 35,8 & 51 & 20,4 & 42,8 & 28,5 & 8 \\
\hline IV & 39,2 & $5 z^{\prime}$ & 18,6 & 40 & 31 & $9,{ }^{\prime}$ \\
\hline
\end{tabular}

TABLEAU II

Proportions des espèces de lactobacilles au cours des phases de croissance et de décroissance de la microflore $G+$

(en p. Ioo du nombre de souches isolées par traitement et par phase)

\begin{tabular}{|c|c|c|c|c|c|c|c|}
\hline Traitement & $\begin{array}{c}\text { Phases } \\
\text { d'isolement } \\
\text { jours }\end{array}$ & $\begin{array}{l}\text { Nombre } \\
\text { de souches } \\
\text { isolées }\end{array}$ & $\begin{array}{l}\text { L. plan- } \\
\text { tarum }\end{array}$ & L. casei & $\begin{array}{c}\text { Lacto- } \\
\text { bacilles } \\
\text { hétéro- } \\
\text { fermen- } \\
\text { taires }\end{array}$ & $\begin{array}{c}\text { Lacto- } \\
\text { bacilles } \\
\text { " ramifiés" }\end{array}$ & $\begin{array}{c}\text { Non } \\
\text { identifiés }\end{array}$ \\
\hline $\mathrm{T}$ & $\begin{array}{l}0-8 \\
9-98\end{array}$ & $\begin{array}{l}70 \\
70\end{array}$ & $\begin{array}{l}2: 3 \\
16\end{array}$ & $\begin{array}{l}4 x \\
37 \\
37\end{array}$ & $\begin{array}{l}26 \\
26\end{array}$ & $\begin{array}{r}4 \\
17\end{array}$ & $\begin{array}{l}3 \\
4\end{array}$ \\
\hline I & $\begin{array}{l}0-8 \\
9-98\end{array}$ & $\begin{array}{l}45 \\
48\end{array}$ & $\begin{array}{l}46 \\
23\end{array}$ & $\begin{array}{l}42 \\
33\end{array}$ & $\begin{array}{r}0 \\
25\end{array}$ & $\begin{array}{l}12 \\
12\end{array}$ & $\frac{0}{7}$ \\
\hline II & $\begin{array}{r}0-12 \\
13-98\end{array}$ & $\begin{array}{l}56 \\
45\end{array}$ & $\begin{array}{l}87 \\
53\end{array}$ & $\begin{array}{r}7 \\
27\end{array}$ & $\begin{array}{r}11 \\
13\end{array}$ & $\begin{array}{l}2 \\
6\end{array}$ & $\begin{array}{l}4 \\
1\end{array}$ \\
\hline III & $\begin{array}{r}0-15 \\
16-98\end{array}$ & $\begin{array}{l}1,65 \\
3.5\end{array}$ & $\begin{array}{l}38 \\
5 ?\end{array}$ & $\begin{array}{l}32 \\
32\end{array}$ & $\begin{array}{r}4 \\
12\end{array}$ & $\begin{array}{r}18 \\
3\end{array}$ & $\begin{array}{l}8 \\
0\end{array}$ \\
\hline IV & $\begin{array}{r}0-41 \\
45-98\end{array}$ & $\begin{array}{l}56 \\
11\end{array}$ & $\begin{array}{l}45 \\
10\end{array}$ & $\begin{array}{l}41 \\
45\end{array}$ & $\begin{array}{r}5 \\
45\end{array}$ & $\begin{array}{l}5 \\
0\end{array}$ & $\begin{array}{l}4_{1} \\
0\end{array}$ \\
\hline
\end{tabular}

DISCUSSION

\section{Modifications au cours du préfanage}

Le préfanage entraîne des modifications tant dans la fraction glucidique que dans la fraction azotée. L'accroissement des sucres totaux ( $72 \mathrm{p}$. Ioo en $7 \mathrm{~h}$, tabl. I) résulte vraisemblablement de deux processus concomitants : la photosynthèse pen- 
dant la période d'éclairement la plus intense (BONNER, I950), lors du préfanage, et la dégradation enzymatique des polysaccharides et notamment d'hémicelluloses (Dewar, MCDONald et WitTenbury, I963). Cette dernière supposition est à rapprocher de la diminution des hémicelluloses observée parallèlement à l'enrichissement en glucides solubles (tabl. I).

Il est intéressant de noter que le taux maximum de sucres n'a jamais dépassé $4,6 \mathrm{p}$. Ioo de la matière sèche. Or, ce taux est nettement inférieur au minimum indispensable pour assurer une production massive et une accumulation d'acide lactique dans un ensilage non préfané (ZELTER, I960).

Une protéolyse semble toujours avoir lieu au cours du préfanage des plantes fourragères, qu'il s'agisse de luzerne (ZELTER, 1960), de Ray grass (BRADY, I960) ou d'herbe (MAC PHERson et Sr.ATER, I959). L'intensité de ce phénomène peut aller jusqu'à la formation d'ammoniaque comme le montrent nos résultats ainsi que ceux de Brady (I960). En accord avec Mac Pherson, nous trouvons également une augmentation importante d'acide $\gamma$ aminobutyrique. Cet auteur suppose qu'une faible hygrométrie de l'atmosphère au cours du préfanage favorise la transformation de l'acide glutamique en acide $\gamma$ aminobutyrique.

Pendant le préfanage, on observe non seulement l'absence de tout développement bactérien, mais encore une réduction de la microflore. On peut penser que la déshydratation, ainsi que l'irradiation solaire exercent une action inhibitrice. Nous relevons toutefois une micropopulation Gram positive plus abondante que celle trouvée par StrrLing (r953), qui a opéré dans des conditions stériles. Ce fait est probablement dû aux contaminations lors des diverses manipulations du fourrage (STIRLING, I963).

\section{Modifications au cours de la conservation par ensilage}

La confrontation des résultats biochimiques et bactériologiques permet de préciser les effets du préfanage sur le déroulement des fermentations.

\section{Formation d'acide lactique et d'acides gras volatils.}

D'une façon générale le préfanage ralentit la vitesse de croissance bactérienne et réduit le nombre total de bactéries tout au long de la conservation, ce qui a pour conséquence de diminuer l'ampleur des fermentations glucidiques.

Le retard dans l'apparition de la phase de croissance maximale de la microflore Gram positive (tabl. 3) et sa diminution numérique entraînent, durant le premier mois de conservation, un retard et une réduction de la production d'acide lactique, d'autant plus importants que le taux de matière sèche est plus élevé. Il s'ensuit que le $\mathrm{pH}$ des ensilages plus préfanés se maintient longtemps à son niveau initial. L'élévation du taux de sucres au cours du préfanage n'influence donc pas la formation de cet acide. Cette action inhibitrice des fortes teneurs en matière sèche qui s'exerce au cours de la phase initiale de la fermentation a été remarquée par LESSARD, BRIGGS et SCAlETTí (I96I), et par nous-mêmes (résultats non publiés). L'acide lactique produit dans le premier mois est ensuite presque totalement dégradé dans le témoin, alors qu'il s'accumule dans les ensilages préfanés, dont le taux de matière sèche est supérieur à 33 p. Ioo. Cette production lente et continue dans les ensilages III 


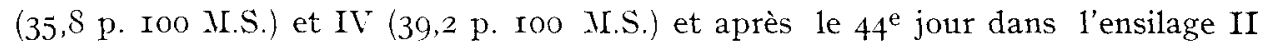
(3I,7 p. roo MI.S.), s'explique par le développement progressif de la microflore Gram positive. Il est possible que ceci soit dû à des disponibilités en réserves nutritives encore assez importantes, alors qu'elles seraient épuisées dans le témoin où l'on assiste à une régression de cette microflore à partir du io jout.

La prédominance des lactiques dans la microflore des ensilages préfanés avait déjà été entrevue par ORTH (I96I). La comparaison de nos cinq ensilages la confirme (fig. 7). De plus, les ensilages préfanés présentent une plus forte proportion de $L$. plantarum, et de streptocoques.

En fin de conservation, le taux maximum d'acide lactique est enregistré dans l'ensilage moyennement préfané (3I,7 p. roo de $\mathrm{Mr} . \mathrm{S}$.), où le développement clostridien est insignifiant. I)ans cet ensilage, on trouve d'ailleurs une population à Gram positive assez comparable numériquement à celle đu témoin, ainsi que la plus forte proportion de L. plantarum parmi les lactiques. Nos résultats ainsi que ceux de Murdoch (Ig60), et de LESSARD, BRIgGs et SCAIE'T'TI (Ig6I) suggèrent pour la luzerne l'existence d'un intervalle de concentrations de matière sèche (aux environs de $30 \mathrm{p}$. Ioo), pour lequel la teneur en acide lactique est maxima dans le produit final. Fin-deçà, l'acide lactique formé en début de conservation est dégradé et audelà sa production est faible.

Une élévation de matière sèche de 5,3 points (taux initial de M.S. = I9,9 p. Ioo) suffit à réduire notablement le catabolisme de l'acide lactique et une augmentation de 16 points (III) l'enraye totalement pendant les 3 premiers mois de la conservation (durée de notre expérience). Ce fait peut expliquer l'inhibition presque totale du développement clostridien par le préfanage : en fin de conservation, le nombre de Clostridia fermentant le lactate atteint par g de M.S. 5 millions dans le témoin Io0 000 dans le moins préfané et reste inférieur à I 000 pour les autres traitements (tabl. 5). Il en résulte que seuls l'ensilage témoin et le moins préfané contiennent de l'acide butyrique. Dans ces deux cas le développement clostridien ne devient notable qu'après 40 jours de conservation. Ie ce fait, nous aurions peut-être obtenu une faible fermentation butyrique dans II et même dans les plus préfanés en prolongeant la conservation de plusieurs mois, comme ce fut le cas dans le travail de I.ESSARD (I 960). Il est donc possible que le préfanage n'agisse pas en inhibant totalement, mais en retardant le développement clostridien.

Toutefois, la dégradation de l'acide lactique qui prend effet après le $3^{\circ}$ jour dans le témoin n'est suivie qu'après le $44^{\mathrm{e}}$ jour d'apparition d'acide butyrique, contrairement à ce que l'on aurait pu attendre d'après les résultats de ZELTER (I960). Ce fait n'est pas surprenant, car si la population clostridienne fermentant le lactate đouble seulement entre le $30^{\mathrm{e}}$ et le $44^{\mathrm{e}}$ jour, elle décuple au $44^{\mathrm{e}}$ jour en passant de 420000 à 5 millions $/ g$ de M.S. Nous ne saurons expliquer le devenir de l'acide lactique disparu dans la première période.

Il semble donc certain que dans nos conditions expérimentales, 1'inhibition de la fermentation butyrique n'est pas due à une production massive d'acide lactique au début de la conservation, pas plus qu'à un abaissement du $\mathrm{pH}$; les modifications au sein de la microflore lactique où la prédominance des lactobacilles est en nette régression pourraient en être responsables. BLAU (I950) a isolé en particulier une souche de Str. faecalis, espèce que nous avons trouvée en quantité relativement importante dans les ensilages les plus préfanés, susceptible d'inhiber le développe- 
ment de $\mathrm{Cl}$. butyricum. Il est donc probable que les antagonismes bactériens jouent un rôle important. Il ne faut pas non plus exclure l'intervention d'altérations de nature physique, telle que l'augmentation de la pression osmotique (Minin, I940 et WIERINGA, I959).

La fermentation acétique est imputable aux actions conjuguées de la microflore Gram négative en début d'ensilage (Govet, FATIAxoFF, I964), des lactobacilles hétérofermentaires (WIERINGA, I959) et des Clostridia. La diminution de la microflore totale, la réduction du pourcentage de lactobacilles hétérofermentaires surtout pendant le premier mois, et l'inhibition du développement clostridien, constatées lorsque le taux de matière sèche s'élève, expliquent que l'on trouve moins d'acide acétique dans les ensilages préfanés à tous les stades de la fermentation (fig. 2).

Protéolyse et ammoniogenèse.

La formation d'azote non protéique n'a été que légèrement limitée par l'élévation du taux de M.S. (fig. 3). La dégradation des protéines est très intense pendant les dix premiers jours de la conservation, ce qui a déjà été remarqué antérieurement (ZELTER, et DURANd-Salomon, I960). Ce catabolisme serait dû principalement à l'action des protéases végétales (Gouter, et FATraxofF, I964) dont l'activité serait optimale pour un $\mathrm{pH}$ de $5,2-5,7$ (SINGH, Ig62) qui est celui de nos ensilages. Le préfanage agit donc moins sur les enzymes végétaux que sur le développement bactérien.

En revanche le préfanage atténue les réactions de transformation et de dégradation des acides aminés et amides libres (fig. 4, 5, 6) : les acides aminés particulièrement labiles (thréonine, acide glutamique, acides aminés basiques) sont protégés alors que $1^{\prime} \alpha$ alanine, les acides $\alpha$ et $\gamma$ aminobutyriques sont formés en moindres quantités. Ces modifications dans la composition en acides aminés libres de l'ensilage de luzerne ont déjà été relevées par ZELTER et DURAND-SALOMON, (I960), et peuvent être dues au métabolisme azoté des microflores Gram négative et surtout clostridienne inexistante dans les préfanés.

Les études effectuées sur les facteurs d'induction de la germination des spores de Bacillus (Schmidt, I957; HERMIER, I962) soulignent le rôle de certains acides aminés dont $1^{\prime} \alpha$ alanine, et la valine. Sans prétendre que ces acides aminés soient aussi à l'origine du développement des Clostridia dans l'ensilage témoin, on peut toutefois remarquer qu'ils y sont présents en quantités importantes.

L'ampleur de l'ammoniogenèse varie en raison inverse de l'intensité du préfanage. La faible densité du peuplement bactérien dans les ensilages préfanés durant les ro premiers jours de la conservation peut expliquer la moindre production d'ammoniaque.

Ultérieurement (après le $3^{\mathrm{e}}$ jour), il est intéressant de mettre en parallèle, dans les ensilages III et IV, l'absence d'ammoniogenèse, l'absence de catabolisme de l'acide lactique et l'absence de production d'acide butyrique. Ces trois faits sont liés à l'inhibition du développement clostridien par le préfanage, ce qui semble montrer que la phase tardive de l'ammoniogenèse dans les ensilages T (I3,9 p. roo de M.S.) et I (25,2 p. Ioo de M.S.) est d'origine essentiellement clostridienne.

Il nous semble intéressant de rapprocher des résultats biochimiques les décalages dans l'apparition de la phase stationnaire bactérienne soulignés dans les tableaux 2, 3 et 4 . Dans les ensilages $T$ et.I, à l'exception des Clostridia, la phase de multiplication bactérienne et de fermentation active a duré environ 8 jours. Les populations

Annales de Biologie animale. - r965. 
bactériennes de ces deux ensilages ont donc trouvé leur équilibre dans un milieu dont la composition quantitative et qualitative en formes azotées solubles aussi bien qu'en glucides et en acides organiques était sans cesse remaniée. Par contre, les ensilages II et surtout III et IV ne présentent leur phase stationnaire que du $20^{\mathrm{e}}$ au $30^{\mathrm{e}}$ jour. Leur population bactérienne s'est donc implantée dans un milieu dont la composition était à peu près stabilisée. Ces situations différentes pourraient concourir à expliquer l'origine des écarts entre proportions de streptocoques et de lactobacilles dans les différents ensilages, mais le pourcentage inattendu de streptocoques dans I ne le serait pas pour autant.

En somme, cette étude cinétique apporte quelques précisions relatives au mode d'intervention du préfanage dans l'établissement de la microflore, qui conditionne les fermentations de l'ensilage. Trois faits sont à souligner :

- le ralentissement du taux de croissance de l'ensemble de la microflore et la diminution de la croissance totale:

- les modifications qualitatives de la microflore Gram positive;

- l'inhibition du développement des Clostridia.

Logiquement, on est conduit à penser que ces phénomènes peuvent être dus à des modifications physicochimiques du milieu consécutives au préfanage : la déshydratation partielle en élerant la concentration du contenu cytoplasmique (éventuellement la pression osmotique d'après Minis, I940 et WIERIxGA, I959), et en retardant ou en supprimant la plasmolyse (GREENHILI, I964), limiterait l'accessibilité immédiate d'éléments nutritifs indispensables à la croissance bactérienne. Cette thèse semble plausible à la lumière des résultats de l'ensilage III : la fermentation lactique y est fortement retardée et atténuée bien que le taux en sucres solubles ait presque doublé au cours du préfanage.

Dans nos conditions expérimentales, un taux de MI.S. de 3I,7 p. Ioo a été suffisant pour empêcher la production d'acide butyrique. Par contre, le taux de $35 \mathrm{p}$. Ioo paraît plus favorable, car il inhibe davantage l'ammoniogenèse. Étant donné la similitude de l'évolution de l'ensemble des fermentations dans les ensilages III et IV, ce taux apparaît suffisant pour l'obtention d'un ensilage de luzerne de très bonne qualité.

I1 est possible que les conclusions précédentes ne soient pas transposables à la technique de "hayllage " (fourrage mi-fané à un taux de matière sèche généralement supérieur à $5^{\circ} \mathrm{p}$. IOo). Les concentrations très élevées en matière sèche, créent vraisemblablement un milieu différent de celui des ensilages préfanés classiques, tels que nous les avons expérimentés.

Reçu pour publication en octobre 1964.

\title{
SUMMARY
}

\author{
INFLUENCE OF RAISING THE DRY MATTER CONTENT ON THE BIOCHEMICAL \\ AND BACTERIOLOGICAL DEVELOPMENT OF A LUCERNE CONSERVED BY ENSILAGE
}

A second lucerne cut was ensiled, with different dry-matter contents (control 19.9, 25.2-3 I.7, 35.8-39.2 p. xoo) produced by prolonging the prewilting process. 
For each treatment, samples were taken $3,5,8$, 10, I 2, 15. 22, 30. 44 and 98 days after placing in the silo. The development of the biochemical and bacteriological phenomena was studied. The following were taken as criteria :
glycidic catabolism (content of lactic acid and volatile fatty acids) ; non-protein nitrogen, free amino acids and ammonial $\mathrm{N}$; total microflora count, Gram-positive, sporulated anaerobic ; analysis of the sequence of the main Gram-positive bacterial species.

The process of prewilting involves a reduction in the rate of growth of the microflora, a diminution of the total growth and an inhibition of development of Clostridia. Qualitative modifications of the microflora were recorded : an increase in the proportion of lactif organisms in the total microflora, a fall in that of the lactobacilli in the Gram-positive microflora in favour in the streptococci and a rise in the proportions of L. plantarum and Str. faecalis. The heterofermenty lactobacilli are not numerous and appear at a late stage. The rise in dry-matter content modifies the glycidic fermentations. In the control, production of lactic acid takes place in the first month. This acid is then degraded and butyric acid is produced. The prewilting process retards and reduces the production of lactic acid which continues throughout the period of conservation. The formation of butyric acid is completely inhibited after the dry matter content reaches $3 \mathrm{I}$ p. Ioo. There is a parallel reduction in acetic acid fermentation.

Amino acid catabolism and ammonia production are interfered with markedly, whereas protein degradation is only slightly reduced.

A dry matter content of $35 \mathrm{p}$. Ioo seems to suffice to give a favourable direction to the conservation process under the conditions of our experiment. 'This action seems to be due to the physiochemical modifications consequent upon the prewilting. The retardation of plasmolysis and the increase in the osmotic pressure would limit the immediate accessibility of nutrient elements indispensable to bacterial growth.

\section{RÉFÉRENCES BIBLIOGRAPHIQUES}

BLAU T., I950. Bakteriostatische wirkung von Milchsaürestreptokoken auf Buttersaürebazillen. Milchwissenschail, 5, 149 - I 5.3 .

Bonner J., 1950. Plant biochemistry, 302-307. Academic Press inc., Publishers, New York ro, N.Y.

Bourdet A., HÉrARD J., 1958. Influence de l'autolyse des levures sur la composition phosphorée et azotée des vins. Inn. Technol, 2, 1 77-202.

BRADY C. J., Ig60. Redistribution of nitrogen in grass and leguminous fodder plants during wilting and ensilage. J. Sci. Fid Lgric., 11, 276-284.

De Man J. C., Rogosa M., Simpre E., ig6o. A medium for the cultivation of lactobacilli. 7 . Appl. Bact., 23, I $3^{0-135}$.

Dewar W. A., McDonald I', Whittenbury R., I963. The hydrolysis of grass hemicelluloses during ensilage. f. Sci. Fid Igric., 14, 411-417.

Dijkstra N. D., Brandsua S., i 955 . Experiments on silage making by the wilting. Method. Versl. Landbowwk. Orders., 61, 5-21.

Elliker P. R., Anderson A. W., Hannesson G., i956. An agar culture medium for lactic streptococci and lactobacilli. J. Dairy Sci., 39, 161 1-1612.

GIBSON 'T', ABD-EI-MALEK, I945. The formation of $\mathrm{CO}_{2}$ by lactic acid bacteria and Bacillus licheniformis and a cultural method of detecting the process. J. Dairy Res., 14, 35-50.

Gouet P., Fatianoff N., ig64. Les bactéries de l'ensilage. I. Tentative de différenciation entre les actions enzymatiques des cellules végétales et bactériennes dans la glycolyse et la protéolyse d'un ensilage de luzerne. Inn. Inst.. Pasteur 107, 7 1 1-72.3.

Greenhill W. I., I964. Plant juices in relation to silage fermentation. II. Factors affecting the release of juices. J. Brit. Grassl. Soc., 2, $23^{\mathrm{I}-2} 3^{6}$.

Hermier J., 1962. La germination de la spore de Bacillus subtilis : I. Action des sucres et des acides aminés sur la phase initiale de la germination. Ann. Inst. Pasteur, 102, 629-643.

JARRIGE R., 196r. Analyse des constituants glucidiques des plantes fourragères. Ann. Biol. anim. Bioch. Biophys., 1, 163-212.

Langston C. W., Irvin H., Gornon C. H., Bouma C., Wiseman R. G., Melin C. G., Moore L. A., MacCalmoNT J. R., 1958. Microbiology and chemistry of grass silage. U. S. D. A., Technical Bubl., $n^{\circ}$ I 187 . 
Langstox C. W., Bouma C., ig60a. Types and sequence change of bacteria in orchard grass and alfalfa silages. J. Dairy Sci., 43, I575-1584.

Langston C. W., Bolm C., I960 b. A study of the microorganisms from grass silage : I. The cocci. II. The lactobacilli. Ippl. Microbiol., 8, 21 2-23t.

Lessard J. R., Briggs R. A., Scaletti J. V., 1961. The organic acids in silage as determined by gas chromatography. Canad. J. Pli. Sci., 41, 507-5i6.

Mac Pherson H. 'T., Slater J. C., I959. Amino- $n$-butyric, aspartic, glutamic and pyrrolidonecarboxylic acid : their detemination and occurrence in grass during conservation. Biochem. J., 71, 655-66o.

Mrhis, 1940. in Xisir I. J., 1959. Partial wilting of grass crops for silage. J. Brit. Grassl. Soc., 14, $107-116,177^{-1} 82$.

Murdocil J. C., 1960. The effect of prewilting herbage on the composition of silage and its intake by cows. J. Bril. Grassl. Soc., 15, 70-73.

Nasu I. J., 1959. Partial wilting of grass crops for silage. J. Brit. Grassl. Soc., 14, 107-I I6 (Experimenta silages) ; I 77-182 (Farm silages).

ORTH 1., KaUffMaxx W., Koch G., ig6o. Mikrobiologische un chenische Untersuchungen zur Frage cies Garverlaufes bei Anwelksilage. Futterkonservierung, 1, I-гo.

ORTH A., KAtFimaxi W., Koci G., 196r. Untersuchungen and Anwelksilagenl. Futterkonservierung 3, I4I-I5I.

Rogosa il., Wiseman R. F., Jorce A. M., Disraely M. N., Beaman A. T., i953. Species differenciation of oral lactobacilli from man including descriptions of Lactobacillus salivarius n. sp. and Lactobacillus cellobiosus n. sp. J. Bact., 65, 681-6c9.

Rosenberger R. F., r95i. The development of methods for the study of obligate anaerobes in silage. Proc. Soc. Appl. Bact., 14, I6I-164.

Schmint C. F. 1957. In Spores 5,58, edited by H. O. Halvorson-American Institute of Biological Sciences, Washington $\mathrm{D}$. C.

Sharpe E., 1955. The selective action of thallous acetate for lactobacilli. J. Appl. Bact., 18, 274.

Sharpe E., Ig62. Taxonony of the lactobacilli. Dairy Sci. Abs., 24, Iog-I I8.

Singh X., 1962. Proteolytic activity of leaf extracts. J. Sci. Fd Agric., 13, 325-332.

Somogri II, 1952. Note on sorgho determination. J. Biol. Chem., 195, 19-23.

Stirlixg A. C., I95I. Bacterial changes in experimental laboratory silages. Proc. Soc. Appl. Bact., 14, $15 \mathrm{I}-156$.

Stirling A. C., 1953. Lactobacilli and silage making. Proc. Soc. Appl. Bact., 16, 27-29.

Stirins; A. C., Wimttenbery R., 1963. Sources of the lactic acid bacteria occurring in silage. J.Appl. Bact. 26, 86-90.

Wierixga G. W., I958. The effect of wilting on butyric acid fermentation in silage. Neth. J. Agric. Sci., 6, 204-2IO.

Wierixiat G. W., 1959. Some factors affecting silage fermentation. II. Influence of degree of laceration and of the bacterial thora from the grass. Neth. J. Agric. Sci., 7, 237-241.

Zelter S.Z., Salomos M., 1959. Conservation par ensilage d'une luzerne en vert. Ann. Zoot., 8, I47-1 73. Zelter S. Z., ig6o. Fermentative behaviour of lucerne ensiled by different methods. Proceed. 8th Internat. Grassl. Congr. Paper $3 \mathrm{~B} / 5$. 